\title{
An implementation framework for developing cities - the way to smart mobility
}

DOI: https://doi.org/10.7307/ptsm.2020.7

\author{
Beti Angelevska ${ }^{1}$, Vaska Atanasova $^{1}$ \\ Faculty of Technical Sciences, University “St. Kliment Ohridski”, Bitola, Republic of North Macedonia ${ }^{I}$
}

\section{Keywords: smart mobility developing cities sustainability environment}

\begin{abstract}
The smart mobility is a concept, where with various past and real-time data, and with the help of information and communication technologies, travel time is optimized, resulting in reductions of space usage, road congestion, road accidents and emissions of harmful gases and noise. [1]

For implementation of smart mobility it will be necessary to combine sustainable solutions and smart innovations at the same time. This will contribute for moving forward in developing cities, which are lacking behind considering inclusion of smart mobility in their urban transport systems. Also, smart mobility will contribute for improved environmental footprint of urban transport, having in mind that environmental issues (air pollution in particular) in these cities are very serious. More specifically, the paper identifies implementation framework for smart mobility, along with drivers and barriers for its implementation, as well as strategies in transport that are environmentally friendly.

Turning carbon-dependent transport sector in developing cities into a clean and smart mobility system might seem like a mission impossible. But, it can be done and it is also a must, given the current transport system's impacts on the environment and public health [2]. At the end, this is an indispensable opportunity to start with changes and to build a better and sustainable future.
\end{abstract}

\section{Introduction}

The transport sector has substantial negative impacts on human health and the environment, causing air pollution, noise pollution and habitat fragmentation [2]. The current mix of transport modes and fuels is simply not sustainable. The goal is to build a clean, accessible, coherent, climate-resilient mobility system that greatly contributes to quality of life and well-being.

Smart mobility is a part of the smart city concept, based on optimizing transport sector in urban areas. Optimizing the mobility could be done by introducing new information and communication technologies with a goal to reduce the economic, environmental and time costs. [1]

Developing cities are faced with serious problems: ineffective transport system from one side, and environmental problems caused by that system, from the other. Changes are needed, not just to reduce the problems with congestion, land use, accidents, traffic delays, fuel consumption etc, but also to modernize the whole transport systems and to mitigate environmental impacts. Hence, innovation actions in developing cities should be directed to integration of sustainable solutions and smart innovation into transport system operations. This framework is elaborated in the paper, considering that development of the institutional and regulatory framework should correspond to mobility policy and strategy in developing cities. Presented framework covers also drivers and barriers to smart and sustainable mobility in developing cities, and through the example of the city of Skopje, and integration between sustainable strategies and smart solutions is given, highlighting the expected benefits. 


\section{Smart and innovative mobility}

As mobility technologies are developing rapidly, technology investments will be only a stepping stone. Most important, governments need a comprehensive approach in the entire transport ecosystem, which consists of six elements (figure 1).

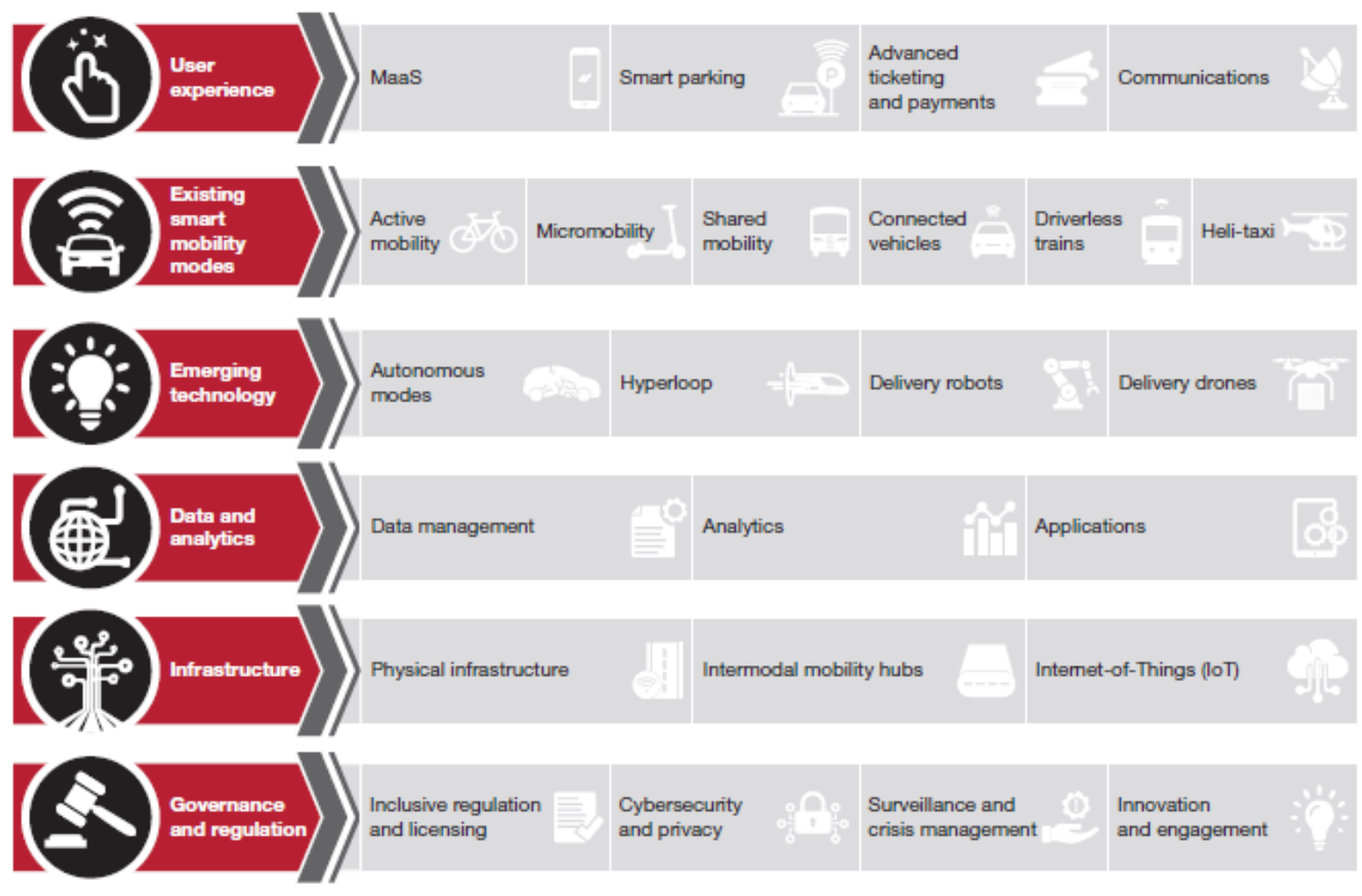

Note: MaaS = Mobility-as-a-Service

Figure 1. The six elements in the smart mobility ecosystem

Source: [3]

Smart mobility can combine different modes and options (public transport, car-sharing, car rental services, taxis and a bicycle system) to cater for mobility needs by using IT, apps, and smart invoicing. Innovation and research will certainly be one of the driving forces behind the transition towards smarter and cleaner mobility. [2]

Innovative solutions can actually challenge some of consumption patterns while still meeting the need for mobility [2]. Innovation does not involve engine designs and energy efficiency only, but also covers new business and ownership models.

Apart of this, smart mobility services and systems will need to interface with multi-sectoral and city-wide strategies for optimizing the use of energy, spatial, economic and material resources [4].

\section{Smart mobility and environment}

In spite of modest, evolutionary innovations, transport continues to represent over $20 \%$ of $\mathrm{CO}_{2}$ emissions and is projected to continue to rise significantly to 2050 [4]. Transport is responsible for a quarter of the EU's greenhouse gas (GHG) emissions. More concretely, transport is the only major economic sector in Europe where GHGs have increased since 1990 and is also the largest contributor to nitrogen oxides emissions, which harm health and the environment. [2] 
The transport sector is estimated to be responsible for up to 50 percent of particulate emissions in developing countries - compared to about 30 percent in developed countries - mostly due to diesel traffic [3].

Recent scenarios offer little confidence that the policy mix currently deployed towards mitigation will have sufficient decarbonisation impact. Projections toward 2050 appear to offer a stabilisation of current absolute $\mathrm{CO}_{2}$ emissions from global transport at best and a rather more probable increase of $\mathrm{CO}_{2}$ emissions, albeit with a reduced rate of increase. [4]

Global trends concerning local air quality, noise levels and climate change put immense societal pressure on research and innovation activities in transport [5]. The overall direction of the transition is clear: towards a combined emerging technologies at vehicles, infrastructure and transport system, as well as in-force regulation. In short, integration of sustainable and smart solutions.

Smart mobility uses innovative digital technologies and solutions to create open and connected transportation networks that can move people and freight more efficiently and sustainably than in the past. By making vehicles and transportation infrastructure technology-enabled and data-informed, smart mobility has the potential to transform society. [3]

Assessments of future development illustrate realistic possibilities to build online data systems with real time information on three specific, transport related data streams [5]:

1. Service supply: on-line, real time information provided by transport suppliers on the main aspects of their services (capacity, route, transfer time, price, etc.).

2. Infrastructure capacity: on-line information on real time traffic streams (intensity) and available capacities of infrastructure, generated by dedicated ITS networks, built into vehicles and into rail/road infrastructure.

3. Impact on climate/environment: on-line information on energy use and air quality/noise aspects of specific transport choices, generated by combining info on chosen vehicle type, transportation mode, real time traffic situation, etc.

A key requirement is for new mobility services to build on zero- and low-carbon technologies, and to contribute to modal shift, efficient demand management and sustainable land use [4].

Smart mobility systems and services have the promise to contribute to the needed decarbonisation of the transport sector and might also help address persistent problems of congestion and accessibility [4].

\section{An example for implementation framework: the city of Skopje}

Population growth and increased urbanization will only exacerbate environmental and health problems caused by transport. Given the scope of the challenges, simply investing in more roads, bridges, and other traditional infrastructure will not be enough. [3] Instead, governments need to rethink their approach to transport and focus on smart mobility.

The city of Skopje is doing modest steps towards sustainability and smart mobility. Roundabounds, cycling and walking paths are already a visible change in the city. Public transport is modernized with new vehicles (although at fossil fuel), and provides real time passenger information and intelligent payment. Zone parking is in function for several years, but smart solutions must further enforce the parking process. The "smartest" solution implemented so far is the centre for traffic management and control, which uses video-cameras at every major crossroad (52 in total), and provides 24 hours control of the traffic flows.

During the autumn-winter, the biggest environmental problem in the city is air pollution, especially with particles. Their level is 6-9 times higher than allowed when the highest pollution occurs. Other environmental problems (noise pollution, vehicle disposal) are also serious, and transport system additionally contributes for their 
deterioration. Hence, the city of Skopje needs to take more dedicated steps towards smart solutions, and this proposed framework is a good starting point.

Developing cities can use smart mobility to reduce traffic congestion, increase road safety, improve the environment, and make transport more accessible and affordable [3].

To use the benefits of smart mobility, and avoid or mitigate the problems, authorities need to learn to manage a fast-moving set of technologies and solutions. They can develop the smart mobility ecosystem through a threestep approach (figure 2).

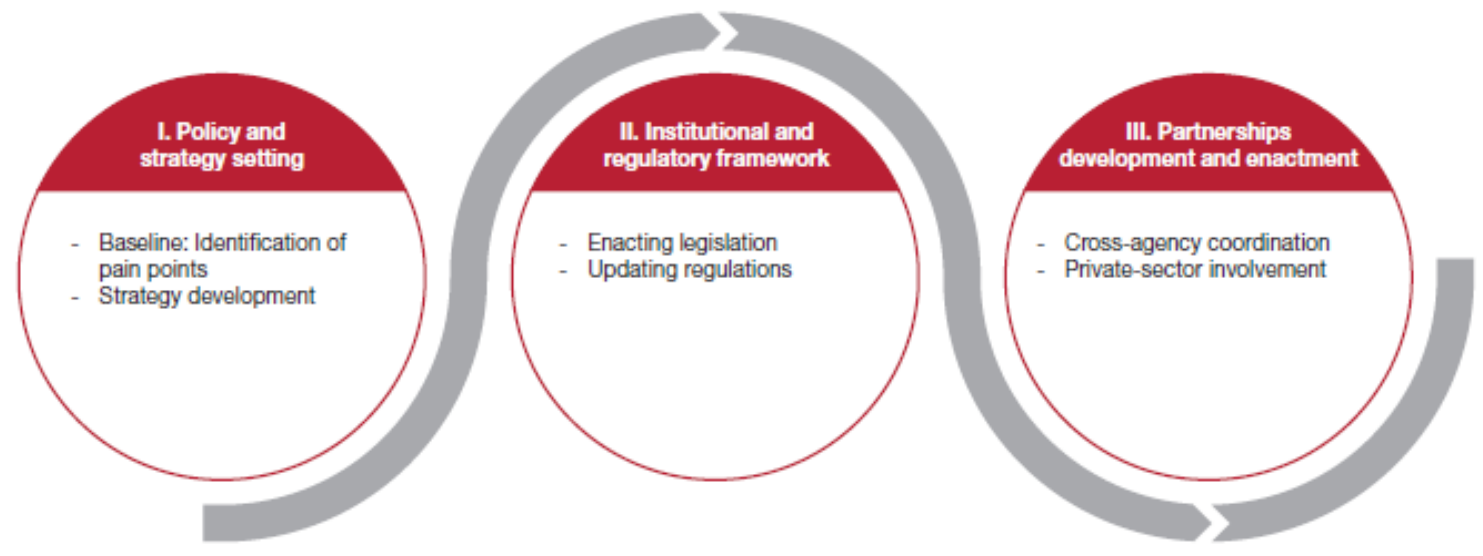

Figure 2. Three steps to promote a smart mobility agenda

\section{Source: [3]}

As has been previously mentioned, integration between sustainability and smart mobility will provide expected results. As an example for integration, table 1 lists various transport emission reduction strategies, considering that currently air pollution is one of the major treats in the environment.

Presented emission reduction strategies are divided into two major categories: cleaner vehicles (more efficient and alternative fuel vehicles which reduce per-mile emission rates), and mobility management. Cleaner vehicle strategies reduce emission rates per vehicle-mile, while mobility management strategies reduce the total vehicle travel.

Table 1: Transport emission reduction strategies

\begin{tabular}{|c|c|c|c|}
\hline Cleaner Vehicles & \multicolumn{3}{|c|}{ Mobility Management } \\
\hline $\begin{array}{c}\text { More Efficient and Alternative } \\
\text { Fuel Vehicles }\end{array}$ & $\begin{array}{l}\text { Improved Transport } \\
\text { Options }\end{array}$ & $\begin{array}{c}\text { Incentives To Choose } \\
\text { Efficient Options }\end{array}$ & $\begin{array}{c}\text { Land Use } \\
\text { Management }\end{array}$ \\
\hline $\begin{array}{l}\text { Efficient vehicle technology } \\
\text { development } \\
\text { Fuel efficiency standards } \\
\text { (such as CAFE) } \\
\text { Alternative fuel requirements } \\
\text { and incentives. } \\
\text { Feebates (financial rewards } \\
\text { for purchasing efficient and } \\
\text { alternative fuel vehicles) } \\
\text { Fuel tax increases }\end{array}$ & $\begin{array}{l}\text { Transit improvements } \\
\text { Walking \& cycling } \\
\text { improvements } \\
\text { Rideshare programs } \\
\text { HOV priority } \\
\text { Carsharing } \\
\text { Telework \& flextime } \\
\text { Taxi service improvements }\end{array}$ & $\begin{array}{l}\text { Congestion pricing } \\
\text { Distance-based fees } \\
\text { Commuter financial } \\
\text { incentives } \\
\text { Parking pricing } \\
\text { Parking regulations } \\
\text { Fuel tax increases } \\
\text { Transit encouragement }\end{array}$ & $\begin{array}{l}\text { Smart growth policies } \\
\text { Transit oriented } \\
\text { development } \\
\text { Location-efficient } \\
\text { development } \\
\text { Parking management } \\
\text { Carfree planning } \\
\text { Traffic calming }\end{array}$ \\
\hline
\end{tabular}

Source: [6]

It is clear that decarbonising transport sector will take time. It requires a combination of measures, including better urban planning, technological improvements, a wider use of alternative fuels, stronger price signals, innovative 
research, continuous adoption of cutting-edge technology and stricter enforcement of existing rules. [2] It also requires all investments in infrastructure and policy measures to be designed to this end.

Applying smart mobility will lead to broader benefits in several areas [3]:

- Safer roads. Vehicle automation (either full or partial) and better safety technology can reduce the number of traffic accidents, leading to fewer roadway fatalities and injuries.

- Less traffic. Smart mobility can move vehicles and people more efficiently over existing roadway networks with less congestion. It can also provide people with alternative options such as shared rides, scooters, bicycles, or mass transit, leading to reduced travel times.

- Cleaner environment. Smart mobility can lead to a reduction in negative environmental effects of the transport sector by providing travellers and transport system operators with more environmentally friendly options.

- More effective workforce. Reinventing mobility will have an important effect on the workforce. Some households will be able to move closer to urban areas (and dispose of private vehicles), increasing their employment prospects and options. Others that choose to move farther away from urban centres can do so as travel times decrease and as autonomous vehicles and other transit options allow commuters to be productive while travelling.

Several developing cities have already incorporated smart mobility into their urban planning. The city of Skopje and other developing cities could use their experience as a good base to build an experience of their own.

\section{Smart and sustainable mobility in developing cities: drivers and barriers}

Smart mobility that make broad use of digital technologies has been touted as possible solution for the population pressures faced by many cities in developing countries and may help meet the rising demand for services and infrastructure. Nevertheless, the high financial cost involved in infrastructure maintenance, the substantial size of the informal economies, and various governance challenges are real obstacles regarding smart mobility. [7]

Rather than just investing in roads and public transit systems, governments need to consider all aspects of smart mobility, including the user experience, transport modes currently in use, more advanced solutions still in development, data and technology, infrastructure, and governance and regulation. Once they have such a comprehensive approach as a foundation, governments need a three-part implementation framework [3]:

1. establish a policy and strategy for smart mobility

2. develop an institutional and regulatory framework

3. collaborate through partnerships and platforms.

The results from the systematic review suggest that eight important driving factors propel the rise of smart city development in developing countries (table 2). Besides technology development, these drivers emphasise the development of economic and financing capacity, as well as the strengthening of regulatory development, human capital, and citizen engagement. In addition, the involvement of the private sector (which tends to have an edge in technology and resources) in creating a supportive ecosystem that promotes innovation will further boost smart city development in developing countries. [7]

Table 2: Drivers for smart mobility development in developing cities

\begin{tabular}{l}
\hline financing capacity of the government \\
\hline building a strong regulatory environment that fosters the confidence and trust of \\
citizens and investors \\
technology and infrastructure readiness \\
human capital \\
stability in economic development \\
active citizen engagement and participation
\end{tabular}


knowledge transfer and participation from the private sector

creating the supportive ecosystem that promotes innovations and learning

Source: [7]

Smart mobility development in developing cities faces exclusive challenges that are fundamentally different from those facing developed countries due to existing socioeconomic challenges (table 3 ).

Table 3: Barriers to smart mobility development in developing cities

\begin{tabular}{l}
\hline budget constraints and financing issues \\
\hline lack of investment in basic infrastructure \\
lack of technology-related infrastructure readiness \\
fragmented authority \\
lack of governance frameworks and regulatory safeguards for smart cities \\
lack of skilled human capital \\
lack of inclusivity \\
environmental concerns \\
lack of citizen participation \\
technology illiteracy and knowledge deficit among the citizens \\
\hline Source: [7]
\end{tabular}

Source: [7]

Governments need to step up their efforts to fulfil the basic infrastructure needs of citizens, raise more revenue, construct clear regulatory frameworks to mitigate the technological risks involved, develop human capital, ensure digital inclusivity, and promote environmental sustainability. A supportive ecosystem that encourages citizen participation, nurtures start-ups, and promotes public-private partnerships needs to be created to realize their smart mobility vision. [7]

\section{Conclusion}

Implementing smart technologies into real transport sector brings significant improvements in road safety, congestion, accessibility and affordability, as well as in impact on the environment in general. The implementation of the smart technologies is expected to increase in future years, depending on budgets and funding because of higher awareness to use new and modern technologies in optimising system performance. [1]

Cleaner and smarter transport can actually meet need for mobility, and at the same time deliver many public health benefits, including cleaner air, fewer accidents, less congestion and less noise pollution [2].

This is very important for developing cities, who already struggle with all these problems together with the lack of financial support to implement smart measures. Hence, this presented framework for implementation of smart and sustainable solutions could serve as a starting point with a potential to change behaviour of the authorities and the public toward smart mobility.

City authorities should conduct a thorough assessment of their current mobility challenges to identify the most urgent problems and pain points. They could also use the offered framework, additionally making benefits of the drivers and avoiding barriers to smart mobility.

Next, city authorities need to establish broad policies for the deployment of smart mobility technologies. These policies can be part of a broader national transport vision or, in the absence of a national plan they can become a building block for governments to begin developing such a vision. [3] Every developing city should build a sustainable, smart and comprehensive mobility system that caters to mobility needs by offering a service tailored to user requirements.

Although still in the early stages of development, smart mobility has already changed the way people, goods, and services move. Used correctly, it can reshape cities and transform society. [3] 


\section{References}

[1] Brčić, D., Slavulj, M., et al. The role of smart mobility in smart cities. $5^{\text {th }}$ International Conference on Road and Rail Infrastructure CETRA 2018. 17-19 may 2018, Zadar, Croatia. 1601-1606. DOI: https://doi.org/10.5592/CO/CETR A.2018.812.

[2] European Environmental Agency. Towards clean and smart mobility - Transport and environment in Europe. EEA SIGNALS 2016, 2443-7662. ISBN 978-92-9213-739-7. ISSN 2443-7662. DOI: 10.2800/090074. Copenhagen, Denmark. 2016.

[3] Strategy\& - Part of the PwC network. Smart mobility in GCC cities - Fast track to the future. Strategy\&. Dubai, UAE. 2019.

[4] European Commission. Smart Mobility and services, Expert group report studies and reports. EUR KI02-17-940-EN-N. EPUB ISBN 978-92-79-71850-2. ISSN KI-01-17-928-EN-N. DOI: 10.2777/490085. Brussels, Belgium. 2017.

[5] Hofhuis, P., Luining, M., Rood, J. EU Transition Towards Green and Smart Mobility - Action Toolbox to Unleash Innovation Potentials. Clingendael Report. Netherlands Institute of International Relations. Hague, The Netherlands. 2016.

[6] Litman, T., Smart transportation emission reduction strategies identifying truly optimal ways to conserve energy and reduce emissions. Victoria Transport Policy Institute. Victoria, Canada. 2017.

[7] Tan, S., Y., Taeihagh, A. Smart city governance in developing countries: a systematic literature review. Sustainability 2020, 12, 899, 1-29. DOI:10.3390/su12030899. 